\title{
Water imbibition of shale and its potential influence on shale gas recovery-a comparative study of marine and continental shale formations
}

\author{
Yinghao Shen a, b, *, Hongkui Ge ${ }^{\text {a, b }}$, Caoxiong Li ${ }^{\text {a, b, d }}$, Xinyu Yang b, c, Kai Ren ${ }^{\text {a, b }}$, \\ Zhihui Yang a, b, Shuai Su ${ }^{\text {a, b }}$ \\ ${ }^{a}$ Unconventional Natural Gas Research Institute, China University of Petroleum, Beijing, China \\ b State Key Laboratory of Petroleum Resources and Prospecting, Beijing, China \\ c CNPC Bohai Drilling Engineering Company Limited, Tianjin, China \\ ${ }^{\mathrm{d}}$ Institute of Mechanics, Chinese Academy of Sciences, Beijing 100190, China
}

\section{A R T I C L E I N F O}

\section{Article history:}

Received 30 May 2016

Received in revised form

14 September 2016

Accepted 18 September 2016

Available online 20 September 2016

\section{Keywords:}

Spontaneous imbibition

Gas shale

Soakback

Hydraulic fracturing

Marine and continental shale

Water blockage removal

\begin{abstract}
A B S T R A C T
A large volume of fracturing fluid is pumped into a well to stimulate shale formation. The water is imbibed into the reservoir during this procedure. The effect of the imbibed water on gas recovery is still in debate. In this work, we study the spontaneous imbibition of water into marine shale samples from the Sichuan Basin and continental shale samples from Erdos Basin to explore the fluid imbibition characteristics and permeability change during water imbibition.

Comparison of imbibition experiments shows that shale has stronger water imbibition and diffusion capacity than relatively higher permeability sandstone. Once the imbibition stops, water in shale has stronger ability to diffuse into deeper matrix, the water content in the main flow path decreases.

Experiments in this study show that marine shale has stronger water imbibition capacity than continental shale. The permeability of continental shale decreases significantly with increasing imbibition water volume; however, the permeability of marine shale decreases at first and increases after a certain imbibition time. The induced fracture is obvious in the marine shale. SEM analysis shows that the relationship between the clay mineral and organic matter of continental shale is much more complex than that of marine shale, which may be the key factor restricting the water imbibition because the flow path is trapped by swelled clay minerals.

Through this study, we concluded that whether gas recovery benefits from water imbibition depends on three aspects: 1 ) the diffusion ability of liquid into matrix; 2) the new cracks introduced by imbibed water; and 3) the formation sensibility. This study is useful for optimizing fracture fluids and determining the best flow-back method.
\end{abstract}

๑) 2016 Elsevier B.V. All rights reserved.

\section{Introduction}

A relatively large volume of fracturing fluid is pumped into a formation to stimulate an unconventional gas formation (Palish et al., 2010; Soliman et al., 2012). The performance of shale hydraulic fracturing shows that a large amount of fracturing fluid (generally more than 50\%) is retained in shale formation after flowback (Engelder et al., 2014). Fast flow-back technique after

\footnotetext{
* Corresponding author. Unconventional Natural Gas Research Institute, China University of Petroleum, Beijing, China.

E-mail address: shenyinghao@126.com (Y. Shen).
}

hydraulic fracturing is used in conventional gas reservoirs to improve flow-back rate and production rate. This technique is meaningful for unconventional gas reservoirs to a certain degree; however, different situations exist in shale gas flow-back and production. Ghanbari et al. (2013) investigated the relationship between flow-back rate and production rate and found that there were quite a portion of wells with low flow-back rate had high production rate. A soak-back technique is then proposed to enhance production after hydraulic fracturing which refers to a period of well shut-in (soaking time) to soak the fracture fluids to improve productivity (Ali Habibi et al., 2015; Dutta et al., 2014).

During this process, water will be imbibed into matrix in the 
fractured reservoir by capillary pressure (Cai et al., 2014) and chemical osmotic pressure (Fakcharoenphol et al., 2014). Fracture fluids imbibition is one key factor that causes fluid loss and low flow-back rate. The effect of water imbibition is still in debate for the shale gas production now (Ali Habibi et al., 2015). Water imbibition has always been recognized as a source that leads to productivity damage in the conventional theory. Spontaneous imbibition will cause formation damage based on the conventional theory of water blockage, especially in unconventional reservoirs with containing extremely small pores with strong capillary pressure (less than $100 \mathrm{~nm}$ ) (Bennion and Thomas, 2005; Roychaudhuri et al., 2013; Odumabo et al., 2014). However, recent studies show that spontaneous imbibition of fracturing fluid can be a driving force to enhance gas recovery in shale gas reservoirs (Dehghanpour et al., 2012; Roychaudhuri et al., 2014). Practices show that additional wells shut-in after fracturing can improve productivity effectively, and a 4.4 fold improvement can be seen in some wells (Yaich et al., 2015). Adding surfactants into fracturing fluids can improve this effect which is approved in Bakken (Wang et al., 2012).

The soak-back technique is to use the spontaneous imbibition of fracturing fluid as a drive force to improve the gas recovery, however; additional wells shut-in pose several bad effects to some wells. Crafton and Noe (2013) and Ghanbari et al. (2013) pointed out that some wells receive productivity loss by well shut-in after fracturing, and the effects are significantly influenced by surfactant additives. Evaluation of "soakback" effect in Marcellus shows that one in four blocks receives a negative effect (Yaich et al., 2015). Thus, studies should urgently determine the potential influence of water imbibition on shale gas recovery (Yan et al., 2015).

Spontaneous imbibition is a natural phenomenon in porous media. Cai and Yu (2012) summarized the research development of the imbibition theory and analyzed the model details including Lucas-Washburn model Terzaghi model, Handy model, Mattax and Kyte model and Aronofsky model. The fractal theory and numerical simulations are also powerful to study the imbibition in complex porous media (Cai et al., 2010, Cai and Yu, 2011). These methods can be used to analyze the fracturing fluids imbibition in shale gas reservoir. However, the imbibition characteristic of different rocks differs and the high clay content made the chemiosmosis play an important role in the process.

There are large potential shale gas resources in the continental environment in China (Zou et al., 2010). According to Wang et al. (2013), continental shale formation is believed to be a promising target in China because of its large area, stable thickness, high total organic content (TOC) and high gas content. Horizontal well drilling and multi-stage hydraulic fracturing technology are used to develop continental shale gas; however, the productivity is much lower than that of marine shale gas in Fuling and Weiyuan of China. The water imbibition may be a key factor affecting this situation.

In this study, we conducted comparative imbibition experiments and permeability experiments on core plugs from the Longmaxi marine shale formation, the Chang-7 continental shale formation and the Xujiahe sandstone formation to investigate the fluid imbibition characteristics and the potential influence on gas recovery.

\section{Samples and methodology}

\subsection{Samples}

The samples are from Longmaxi Marine Shale Formation of Lower Silurian in Sichuan Basin and Chang-7 Continental Shale Formation of Triassic in Erdos Basin.

The Longmaxi shale sample is a fresh core sample from a well drilled at depth of $3328.54-3358.54 \mathrm{~m}$ and is cut into four twin plugs for consistent and comparative imbibition experiments (LMX-1, LMX-2, LMX-3, LMX-4). The thickness of these formations ranges from $60 \mathrm{~m}$ to $420 \mathrm{~m}$. The TOC of the Longmaxi formation is $2.5 \%-8.3 \%$ with an average of $5.2 \%$. The gas content is $1.7-3.3 \mathrm{~m}^{3} /$ ton. The Chang-7 shale sample is a fresh core sample from a well drilled at depth of 1455.33-1458.51 $\mathrm{m}$ and cut into four twin plugs (CH7-1, CH7-2, CH7-3, CH7-4). The TOC of Chang-7 is 3.5\%-6.5\% with an average of $4.7 \%$. This formation has medium gas content of $2.0-5.0 \mathrm{~m}^{3} /$ ton. For comparison purposes, two sandstone samples $(\mathrm{XJH}-1, \mathrm{XJH}-2)$ are chosen from Xujiahe Formation in Sichuan Basin.

The samples were dried at $105^{\circ} \mathrm{C}$ for $12 \mathrm{~h}$ before the experiment until the mass remained unchanged. Sample porosity was measured by helium porosimeter (KXD-III type). The porosity distribution of three types of samples presents certain differences. $\mathrm{XJH}$ sandstone samples have the highest porosity with an average value of $13.22 \%$. LMX samples have higher porosity (average $3.50 \%$ ) than CH7 samples (average 2.37\%). Sample pulse-decay permeability was determined by an ultra-low permeability measurement instrument, confining pressure exerted by water and pore pressure exerted by helium. The following test conditions were used: temperature of $25^{\circ} \mathrm{C}$; confining pressure of $8 \mathrm{MPa}$; and pore pressure of $5 \mathrm{MPa}$. The permeability of $\mathrm{XJH}$ sandstone samples ranged from $2.11 \mathrm{mD}$ to $2.34 \mathrm{mD}$. The range of LMX shale samples permeability varied from $0.0016 \mathrm{mD}$ to $0.0028 \mathrm{mD}$. The permeability of $\mathrm{CH} 7$ shale samples changed from $0.0014 \mathrm{mD}$ to $0.0062 \mathrm{mD}$.

Table 1 provide the rock mineralogy of three kinds of sample based on X-Ray Diffraction (XRD) analysis. The main minerals of LMX shale are quartz (46 wt\%), feldspars (11 wt\%), calcite ( $8 \mathrm{wt} \%$ ), and clay minerals (28 wt\%). Clay minerals of LMX shale mainly consist of illite and mixed layer of illite/smectite, where illite has a portion of $75 \%$. The main minerals of $\mathrm{CH} 7$ shale are quartz (24 wt\%), feldspars (23 wt\%), and clay minerals (49 wt\%). Clay minerals of $\mathrm{CH} 7$ shale are mainly consist of illite and mixed layer of illite/ smectite; however, its illite/smectite content reaches $48 \%$. The main minerals of $\mathrm{XJH}$ sandstone are quartz (40 wt\%), feldspars (27 wt\%), dolomite(13 wt\%) and clay minerals (49 wt\%). Clay minerals of XJH sandstone mainly consist of illite, chlorite and a mixed layer of illite/smectite.

\subsection{Methodology}

First, we measured spontaneous imbibition of distilled water into plugs and compared the main characteristic parameters for the three kinds of sample, including liquid imbibition capacity and liquid diffusion ability. In the imbibition process the conductivity is measured in real time. Then, we conducted two tests to investigate the impact of imbibition to permeability. The first test was set to test the permeability values before and after water imbibition in dry condition where the whole core contacted with liquid. The second test was set to test the permeability during the water imbibition where one side of the core contacted with liquid. The two tests are made to observe the influence of water imbibition to gas permeability more clearly. The inconsistence is negligible here. Finally we conducted Scanning Electron Microscope (SEM) analysis on the samples after imbibition.

\subsubsection{Spontaneous imbibition of distilled water into samples}

In the spontaneous imbibition experiment, distilled water was used as working liquid. The sample contacts the liquid with all surfaces. The schematic is presented in Fig. 1. The imbibed water weight was measured on line by a balance (METTLER LE204E) connected to a computer. The method to obtain the imbibed water weight is shown in Fig. 1. This method can eliminate the influence of water vaporization from the container to the imbibed water weight measurement. The experiments were performed at room 
pressure $(0.1 \mathrm{MPa})$ and temperature $\left(25^{\circ} \mathrm{C}\right)$.

In the imbibition, the water electrical conductivity is measured by a multifunctional conductivity measurement produced by METTLER (SevenExcellence). The electrode used is a normal type solution conductivity electrode, the precision of which is $0.1 \mu \mathrm{S} / \mathrm{cm}$ $2000 \mathrm{mS} / \mathrm{cm}( \pm 0.5 \%)$.

\subsubsection{Permeability test with different water content}

Dry sample permeability and mass were measured as initial permeability and mass, respectively. Then, spontaneous imbibition was conducted on the sample. Here, the sample contacts with the liquid only in one surface via the imbibition device. The schematic diagram of Pulse-decay permeability measurement shown in Fig. 2, and the test principle is as Jones (1997). Rock permeability and mass were measured after sample imbibition at specific time intervals. The surface water of the sample was dried by adsorbent paper. By repeating the preceding steps, a series of permeability values versus imbibition liquid mass was obtained. After experiment completion, the figure of the permeability versus time and the figure of imbibition water mass versus time were obtained in the same coordinate system.

\subsubsection{Microscopic imaging of different samples}

Helios NanoLab 650 Field Emission Scanning Electron Microscopy (FE-SEM) was used to investigate the nano-scale pore structure and the spatial distribution of different samples. The SEM images can effectively represent the clay-organic matter spatial relationship in continental shale and marine shale. They could also be used to observe the surface change between pre- and after water imbibition.

\section{Results}

\subsection{Liquid imbibition capacity}

The liquid imbibition capacity is defined to characterize the rock's water imbibition ability. As shown in Fig. 3 the spontaneous imbibition will approach to stabilization for a certain time. Here we define a parameter $C$ which is the ratio of maximum imbibed liquid volume to pore volume (PV). Fs represents the liquid imbibition capacity for the rock to a certain fluid. The expression of C (Liu Yang et al., 2016) is given as follows:

$C=\frac{V_{\max }}{P V}$

where $V_{\max }$ is the maximum imbibed liquid volume, and PV is the pore volume of the rock.

Fig. 4 shows the ratio of maximum imbibed liquid volume to pore volume of different samples. The average $C$ value of LMX shale samples in the experiments is 1.36 ; however, the average $C$ value of
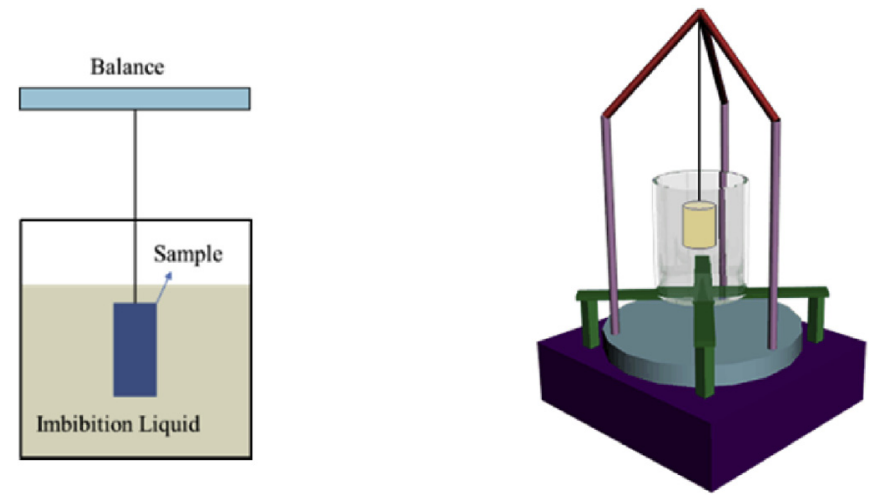

Fig. 1. Schematic of imbibition apparatus(Left: 2D; Right: 3D).

$\mathrm{XJH}$ sandstone samples is 0.43 , which indicates that the LMX shale has stronger liquid imbibition capacity. Here, the $C$ value being higher than 1 is a reflection of other potential effect, such as chemical force and pore space enlargement during the interaction of rock and fluids.

We noticed that not all the shale samples have strong liquid imbibition capacity. $\mathrm{CH} 7$ shale samples have an average $\mathrm{C}$ value (0.33) lower than that of $\mathrm{XJH}$ sandstone samples. This phenomenon indicates that not all the shale rocks have strong liquid imbibition capacity for potential high capillary pressure. Liquid imbibition capacity may be influenced by other factors. For the high mixed layer of illite/smectite content and the complex structure of clay and organic matters, the $\mathrm{CH} 7$ shale sample is easily influenced by hydration and the pore space is reduced by the squeezing action of smectite swelling.

\subsection{Liquid diffusion ability}

The ability of liquid to diffuse into deeper matrix is another important parameter. The capillary part in mainly controlled by the capillary pressure and the imbibed mass is linear to the square root of time (Li et al., 2016a). So the capillary part is a straight line in the $\log$ coordinate, which is easy to recognize. When the capillary pressure and resistance become equilibrium, the capillary part ends and the diffusion past begins which in mainly controlled by chemiosmosis. In the imbibition curve, diffusion ability is defined as the ratio of imbibed liquid mass in the diffusion part to ultimate imbibed liquid mass, as shown in Fig. 5a. In core samples with stronger diffusion effect, the imbibition mass in the diffusion part is relatively larger, which leads to stronger diffusion ability. Thus, the diffusion ability is a representation of the liquid's ability to diffuse into matrix. The capillary part and diffusion parts can be recognized from double logarithm coordinate. As shown in Fig. 5b, the imbibition curve in the capillary part is relatively straight, whereas a

Table 1

Basic property of samples.

\begin{tabular}{|c|c|c|c|c|c|}
\hline Sample & Weight $[\mathrm{g}]$ & Diameter [mm] & Length $[\mathrm{mm}]$ & Porosity [\%] & Dry sample permeability [mD] \\
\hline LMX-1 & 16.13 & 25.12 & 15.01 & 3.54 & 0.0028 \\
\hline LMX-2 & 15.93 & 24.98 & 15.23 & 3.35 & 0.0017 \\
\hline LMX-3 & 15.62 & 24.89 & 14.94 & 2.76 & 0.0013 \\
\hline LMX-4 & 32.57 & 24.89 & 29.78 & 4.32 & 0.0016 \\
\hline CH7-1 & 15.15 & 24.96 & 15.41 & 2.32 & 0.0062 \\
\hline $\mathrm{CH} 7-2$ & 14.43 & 25.02 & 14.83 & 1.35 & 0.0014 \\
\hline $\mathrm{CH} 7-3$ & 14.64 & 24.95 & 14.98 & 2.78 & 0.0032 \\
\hline $\mathrm{CH} 7-4$ & 15.03 & 24.93 & 15.03 & 3.03 & 0.0055 \\
\hline $\mathrm{XJH}-1$ & 15.17 & 24.77 & 15.41 & 13.01 & 2.11 \\
\hline $\mathrm{XJH}-2$ & 15.25 & 24.71 & 15.52 & 13.42 & 2.34 \\
\hline
\end{tabular}




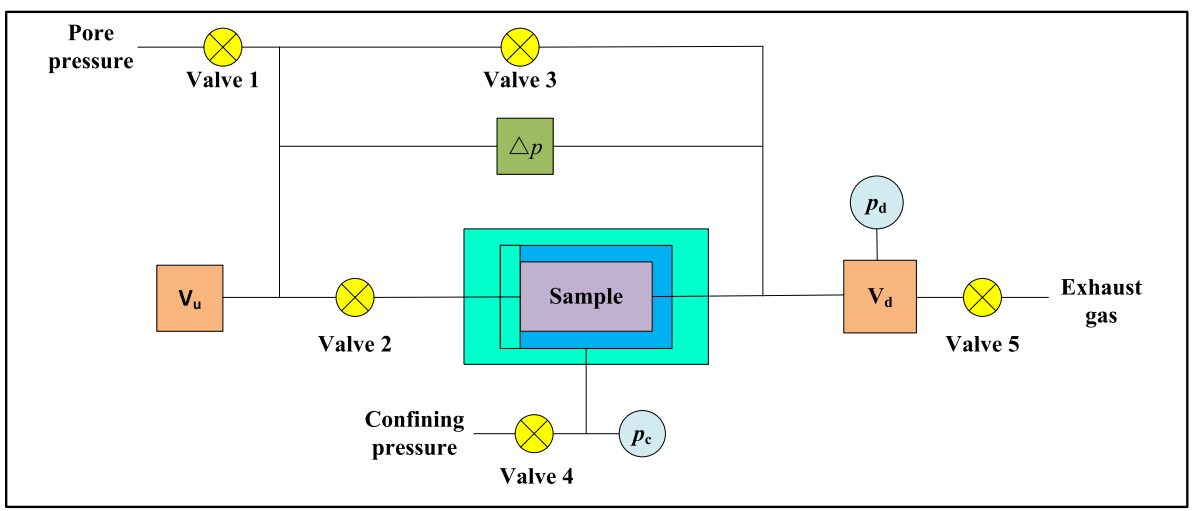

Fig. 2. Schematic of Pulse-decay permeability measurement.

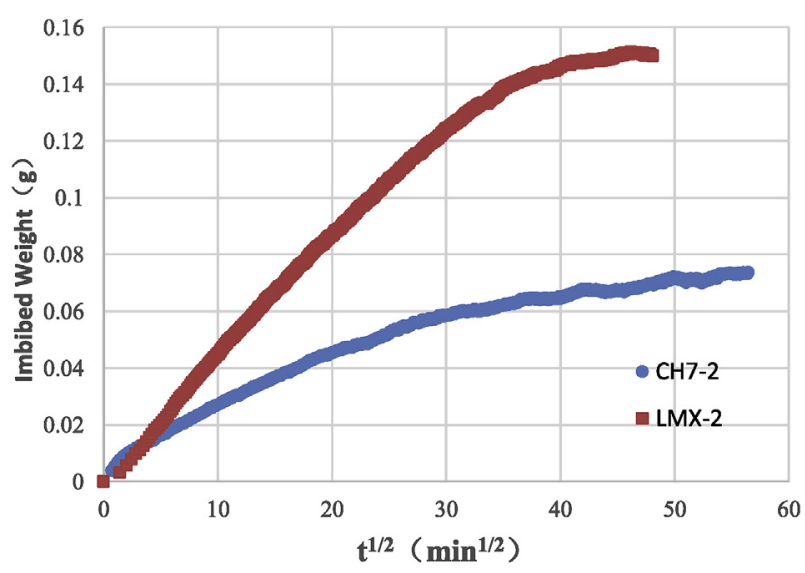

Fig. 3. Imbibition curve of LMX-2 and $\mathrm{CH} 7-2$.

deviation from the capillary part emerges when diffusion effect occurs. Thus, the diffusion part is recognized after the deviation point. We define a parameter $F_{d}$ to represent the liquid diffusion ability, which is given by:

$F_{\mathrm{d}}=\frac{M_{\mathrm{d}}}{M_{\max }}$

where $M_{d}$ is the imbibed liquid mass in the diffusion part, and $M_{\max }$ is the ultimate imbibed liquid mass.

The diffusion abilities of 10 samples are shown in Fig. 6. The average diffusion ability of each sample type is calculated and

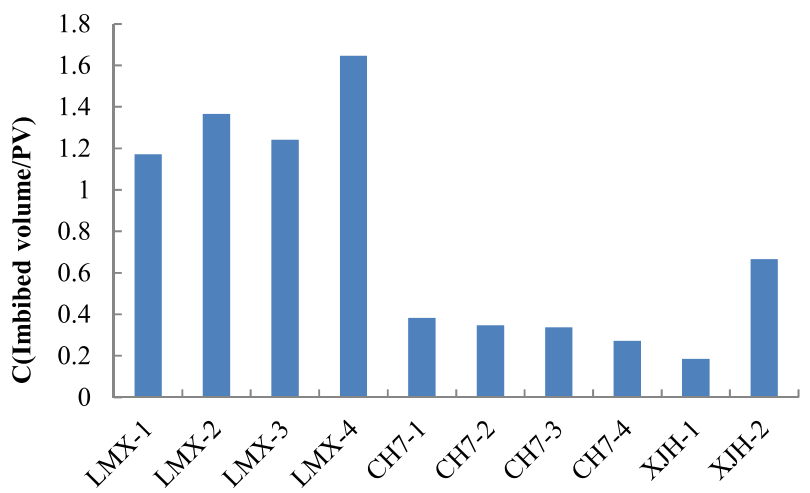

Fig. 4. Ratio of maximum imbibed liquid volume to pore volume of different samples. expressed in the right portion of Fig. 6. The average diffusion ranges from 0.05 to 0.45 . Heterogeneity of data in each rock type is obvious. Statistically, the average diffusion in shale is relatively higher than that in sandstone. More than a quarter of imbibition mass in shale is imbibed in the diffusion part. By contrast, less than $10 \%$ of imbibition mass in sandstone is imbibed in the diffusion part. These data showed that diffusion ability is an important characteristic in shale core, thus, shale formation has strong diffusion ability in shale formation. Additionally, $\mathrm{CH} 7$ shale samples have weaker diffusion ability than LMX shale samples.

\subsection{Water conductivity change during water imbibition}

The electrical conductivity of solution depends on the electrolyte concentration in the solution, which is one important index reflecting by ion content and type in the measuring solution. Here the fluids used are the same. The conductivity change with time indicated the ion change between rock and fluid during water imbibition. Generally, the electrical conductivity gets higher with the higher ion content. We have measured the electrical conductivity of four samples' solutions. As shown in Fig. 7, the electrical conductivity approach to stabilization for a certain time too. The LMX shale has higher conductivity than $\mathrm{CH} 7$ shale.

\subsection{Permeability change due to water imbibition}

The permeability values before and after water imbibition in dry condition are shown in Fig. 8. The permeability values of LMX shale samples are enhanced by $46 \%$ through this process, whereas that of $\mathrm{CH} 7$ shale samples decrease by $43 \%$. Meanwhile the permeability change of $\mathrm{XJH}$ sandstone samples can be ignored, which is in the $+5 \%$ and $-5 \%$ interval.

The changes in both permeability and water content as a function of imbibition time in different kind of samples are shown in Fig. 9. The permeability measured here is in the condition of water in the rock. The pressure decay pulse-decay permeability technique needs a small differential pressure and 50 psi was enough to get the gas permeability and this differential pressure was hard to change the water distribution in the core. The time in Fig. 11 doesn't include the permeability test time which is $10-20 \mathrm{~min}$ one time. The water increases with increasing imbibition process and the permeability changes in different manners for the samples. The marine shale LMX-2's permeability decreases at first and greatly increases after $55 \mathrm{~min}$. The permeability in $140 \mathrm{~min}$ is closed to the original permeability. The marine shale LMX-4's permeability decrease at first and greatly increases after $50 \mathrm{~min}$ and the permeability in $100 \mathrm{~min}$ is closed to the original permeability. The continental 

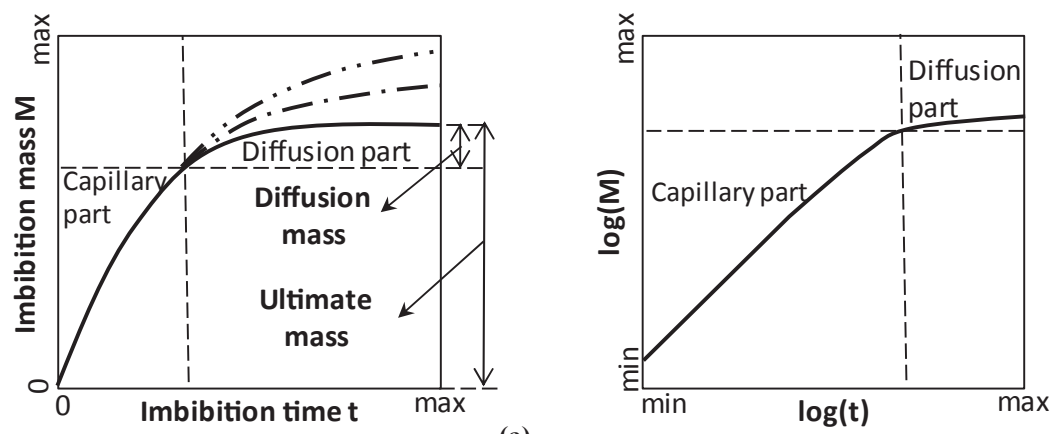

(a)

Fig. 5. Ratio of maximum imbibed liquid volume to pore volume of different samples.

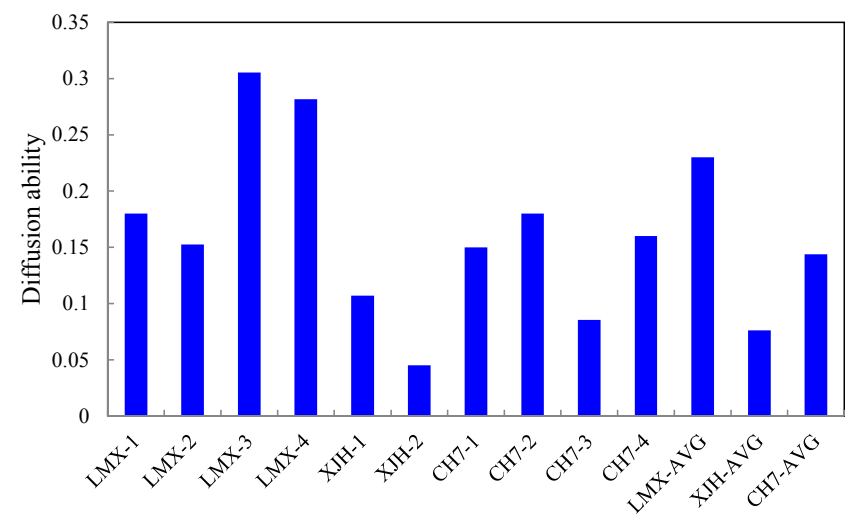

Fig. 6. Diffusion ability of different samples.

shale's permeability decreases sharply after $10 \mathrm{~min}$. The experiments indicate that water intake has various influences, and the shale type may be the key factor.

Fig. 10 shows the pictures after water imbibition, through which we can see that the LMX shale has induced visible fractures. The other two samples have minimal change. At the same time, the induced micro-fracture can be seen under the SEM image. Two new small fractures appeared after $1 \mathrm{~h}$ water imbibition. The SEM images are shown in Fig. 11.

\section{Effect of water imbibition to gas recovery}

The above experiments sec show that the interaction between water and formation is different from two shale formations, which

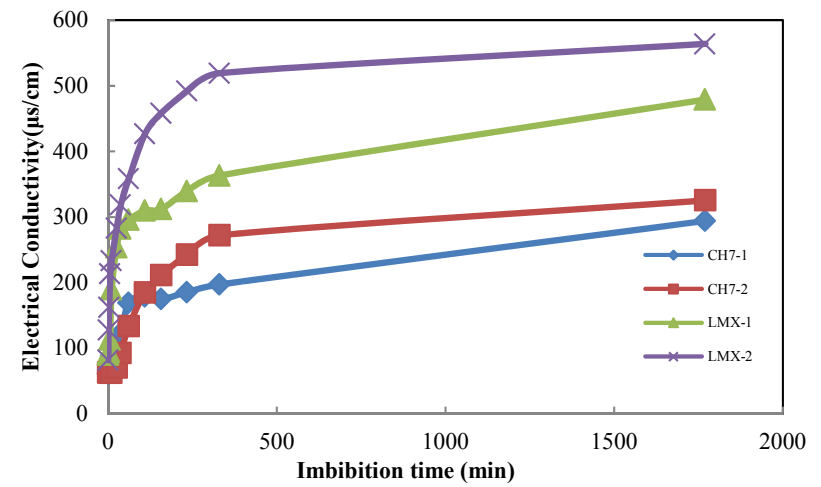

Fig. 7. Electrical conductivity of different samples. may be one important factor affecting the gas recovery using large volume slick water fracturing. The marine gas shale in China achieves a successful development; however, gas recovery in continental gas shale is difficult, even though the gas recourse is huge and advanced fracturing technique is used. In our view, the well productivity in continental gas shale is significantly affected by the large water injected into formation; however, the well productivity in the marine gas shale is minimal to affect the water block removing ability.

4.1. The clay content and the relationship between clay and organic matter have significant influences on water imbibition capacity

The marine shale from Longmaxi formation and the continental shale from Chang-7 formation have different water imbibition characteristics. We conducted the micro-structure observation by using SEM. Figs. 12 and 13 show SEM images under NanoLab 650 performed on different shale samples, respectively. The black part is the organic matter and the gray part shows the other minerals such as quartz and feldspars. Through these images we can see the differences between Longmaxi shale and Chang-7 shale. First, Chang-7 shale has higher clay content than Longmaxi shale. Second, for Chang-7 shale, clay and organic matters are commingled and the organic matters and quartz are scattered into the clay minerals. By contrast, however, for Longmaxi shale the spatial distribution of organic matter can be easily tracked and the spatial relationship with clay minerals is more regular. Finally, the imbibition of water will cause clay swelling and will result in blockage of the micro flow path, which may be the reason causing the lower imbibition capacity of continental shale and the permeability loss after water imbibition.

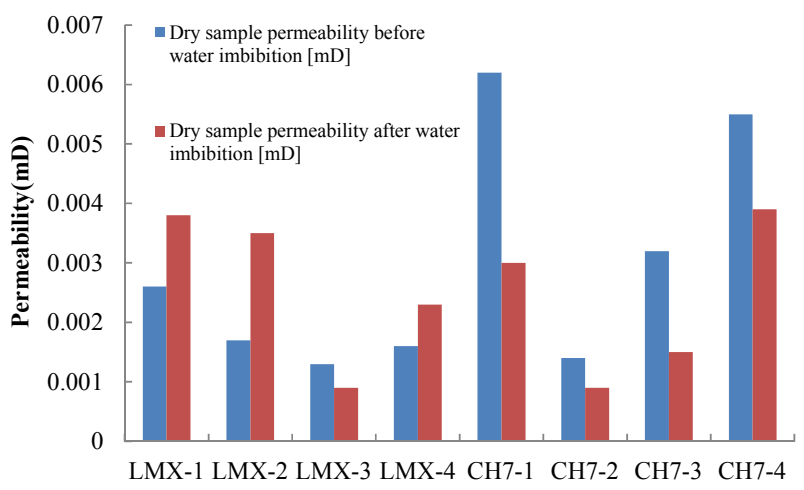

Fig. 8. Permeability change due to water imbibition. 

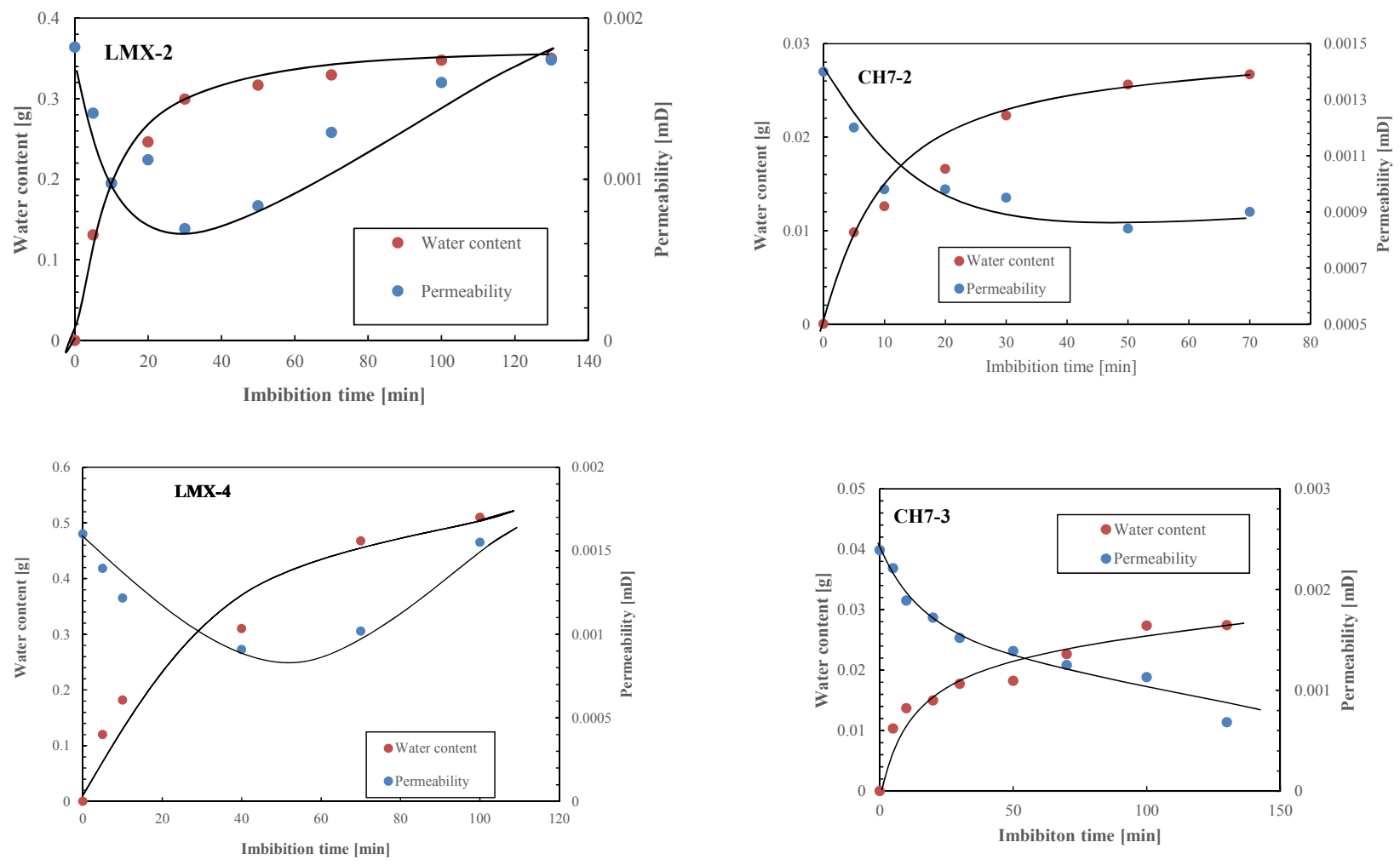

Fig. 9. Change of permeability and water content with imbibition time in different samples.

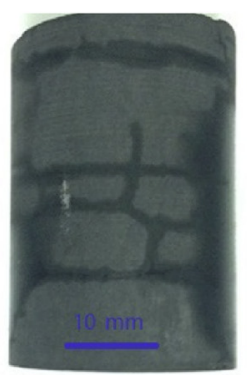

(a)
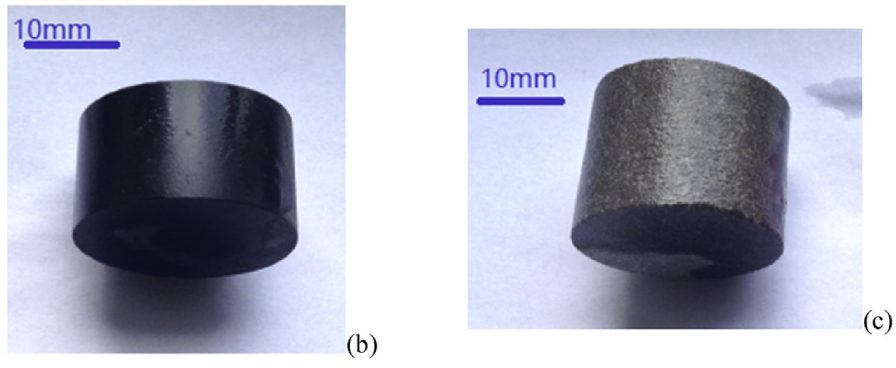

Fig. 10. Sample pictures after water imbibition (from left to right: LMX-4(a), $\mathrm{CH} 7-2(\mathrm{~b}), \mathrm{XJH}-2(\mathrm{c})$ ).

\subsection{The formation should have strong water imbibition capacity}

If the water imbibition capacity is much higher than the water injected, the water will be imbibed into the formation matrix and does not affect the main flow path. The gas can flow out because of low resistance due to the low water content in the main path. The marine gas shale in this study has stronger water imbibition capacity than the continental shale. This finding may be one factor influencing the productivity. In addition, the formation's water imbibition capacity is impacted by formation ion content. Relative
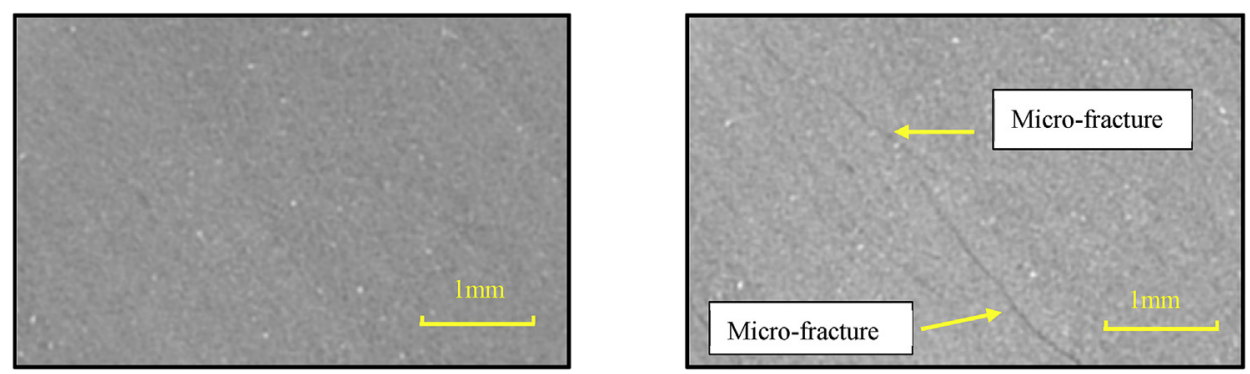

Fig. 11. SEM images of LMX shale sample before and after $1 \mathrm{~h}$ imbibition. 


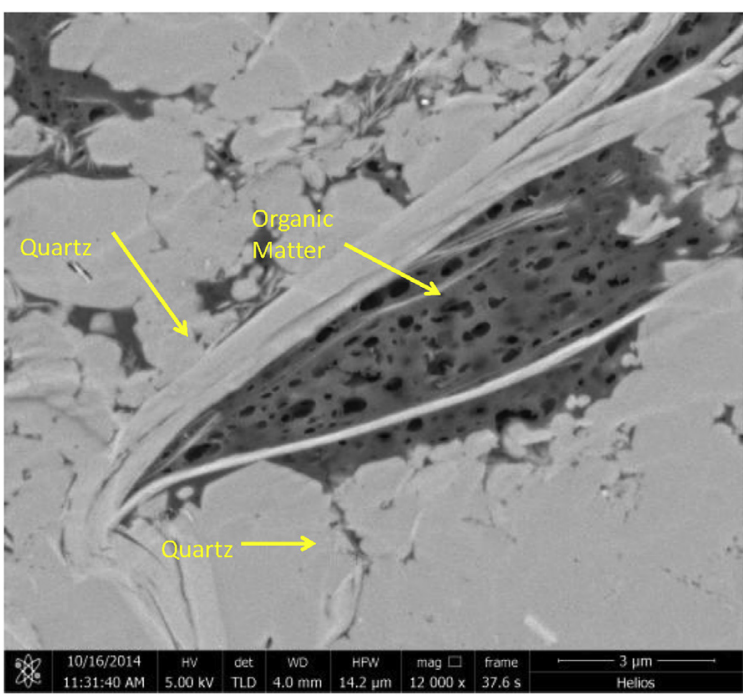

Fig. 12. Backscattered electron images of LMX shale.

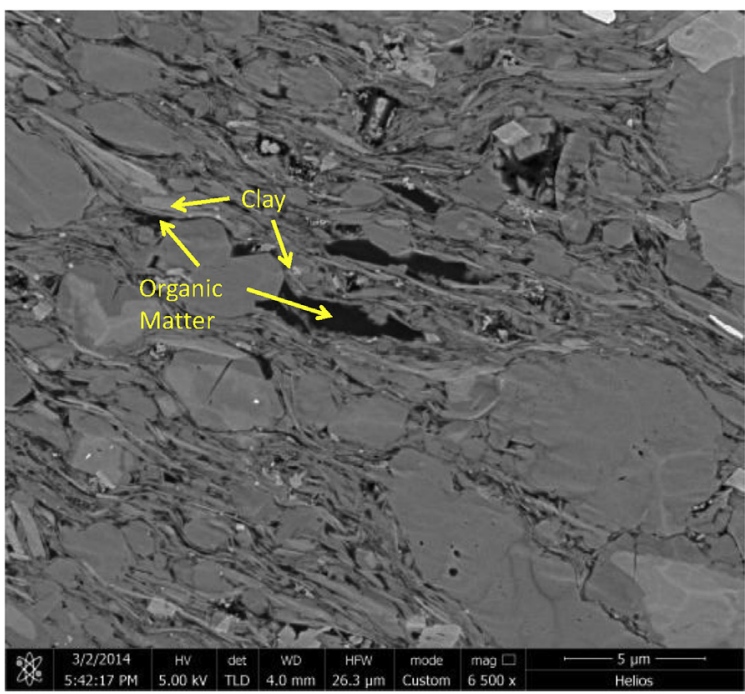

Fig. 13. Backscattered electron images of $\mathrm{CH} 7$ shale.

higher ion content in marine shale is one basic condition for the high osmotic pressure when low salinity fracturing fluids pumped into formation.

4.3. The rock should have liquid diffusion ability to remove the water in the main flow path

The experiments showed that diffusion ability of shale is significantly stronger than that in sandstone, which makes the imbibition effect significant in shale formation. From the experimental data, the shale sample's diffusion ability is about four times larger than that of sandstone.

Pore structure is one of the parameters affecting diffusion ability. The pore structure in the shale matrix has much difference on sandstone. Normally, the pore diameter of shale is much smaller than that in sandstone. Furthermore, shale has many branch throats and micro-nano sub-pores, whereas normal sandstone has large pores with simpler pore structures. These features are shown in the pore size distribution curve. Pore structure has fractal properties in a specific scale, which can be simplified as a special fractal network model (Li et al., 2016a,b) (Fig. 14).

We have discussed the diffusion ability of fractal network model and expressed analytical expression of diffusion (Li et al., 2016a,b). The result shows that abundant micro-nano branches in shale have positive influence on diffusion ability. Capillary force in thin pores is relatively strong. As liquid is imbibed in deeper matrix, numerous micro-nano pores in shale matrix will course strong imbibition force, which leads to large imbibed mass in the diffusion part of imbibition curve. This characteristic can remove blocked water in the main pathway of gas, which will be of advantage for gas to flow (Fig. 15)

\subsection{New cracks introduced by imbibed water}

By analyzing the relationship permeability before and after water imbibition we determined that some shale reservoirs can easily to form micro fracture when water is imbibed into the formation. For gas shale, the induced fracture could increase the effective permeability and reduce the flow resistance of gas in the matrix by using the interaction between fracturing fluid and reservoir, thus making the gas easier to access to the fracture.

The main factors controlling the effect are the mineral composition and content of the shale reservoir. The main mineral composition of LMX shale is quartz and the main clay mineral composition is illite. While the main mineral composition of Chang-7 shale is swelling clay mineral, thus, it fracturing fluid dose not easily to form micro fractures.
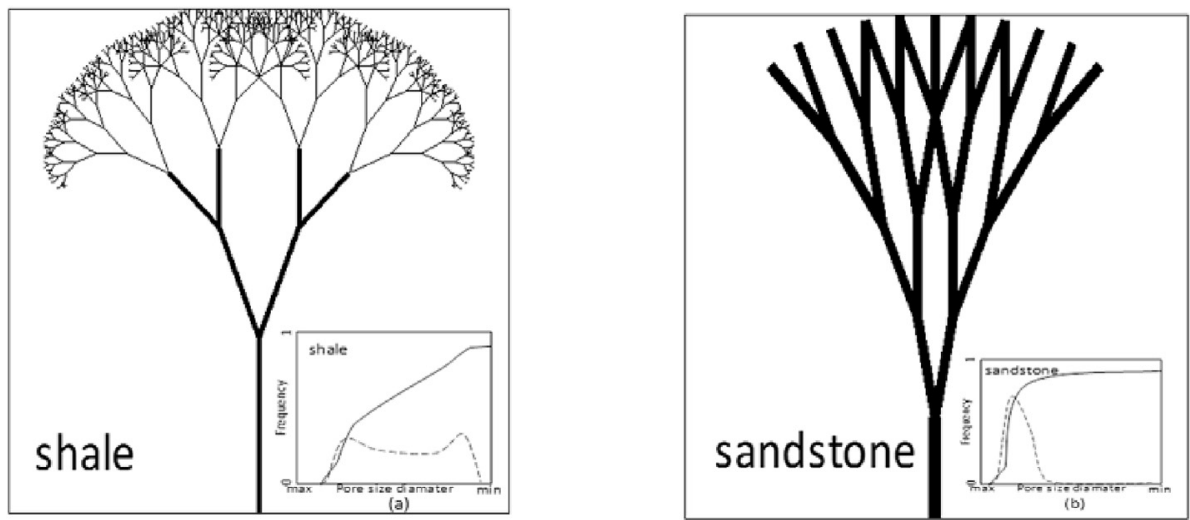

Fig. 14. Special fractal network model for shale and sandstone (Li et al., 2016a,b). 

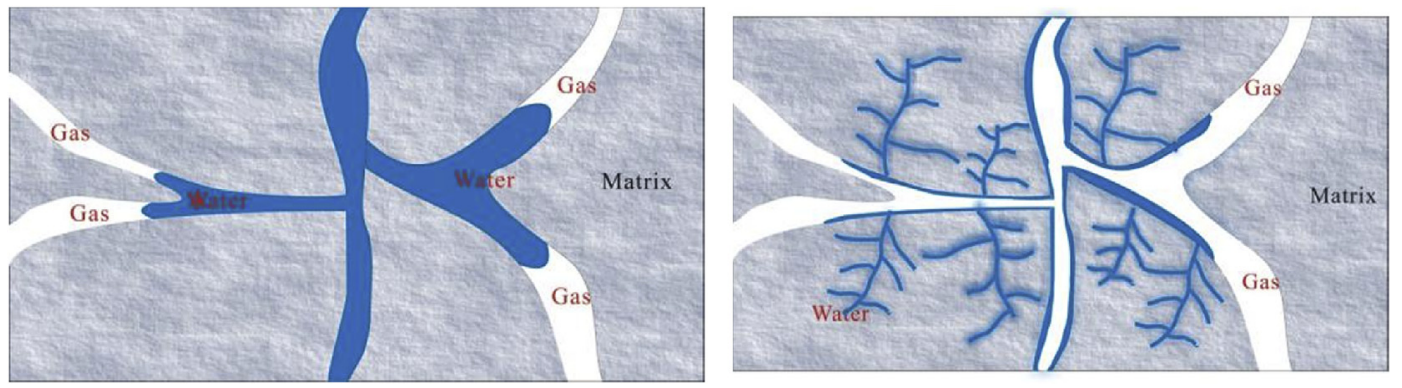

Fig. 15. Water block unlocking effect for diffusion of water into deeper matrix.

\section{Conclusions}

We conducted systematic spontaneous imbibition experiments and obtained the following results: (1) Longmaxi marine shale has stronger liquid imbibition capacity than conventional sandstone and Chang-7 continental shale. Chang-7 continental shale has lowest imbibition capacity because of its high content of mixed layer of illite/smectite and the complex relationship between clay and organic matter. (2) The average diffusion ability of shale is significantly higher than that of conventional sandstone. (3) The fracture induced by water imbibition is one key reason to improve the permeability. Based on the experiments and analysis, the influence of water imbibition to shale gas recovery may exist in the following points.

(1) The ability of liquid to diffuse through matrix is one of the necessary conditions for water blockage removal. If liquid keeps being diffused into deeper matrix, the blocked water in the main pathway will decrease, this will be of advantage for gas flow.

(2) The interaction between matrix and imbibed liquid can produce new cracks and stimulate the extension of natural cracks for most gas shale. New gas flow channels increased in this process can improve the permeability effect.

(3) Formation sensibility is important for shale gas production.

\section{Acknowledgments}

This study was supported by the National Natural Science Foundation of China (51490652, U1562215 and 51604287), the Science Foundation of China University of Petroleum, Beijing (2462015YQ1202), and the Sinopec scientific research project (P15026).

\section{References}

Bennion, D.B., Thomas, F.B., 2005. Formation damage issues impacting the productivity of low permeability, low initial water saturation gas producing formations. J. Energy Resour. Technol. 127 (3), 240-247. http://dx.doi.org/10.1115/ 1.1937420

Cai, J.C., Yu, B.M., 2011. A discussion of the effect of tortuosity on the capillary imbibition in porous media. Transp. Porous Media 89 (2), 251-263. http:// dx.doi.org/10.1007/s11242-011-9767-0.

Cai, J.C., Yu, B.M., 2012. Advances in studies of spontaneous imbibition in porous media. Adv. Mech. 42 (06), 735-754. http://dx.doi.org/10.6052/1000-0992-11096.

Cai, J.C., Yu, B.M., Zou, M.Q., et al., 2010. Fractal characterization of spontaneous cocurrent imbibition in porous media. Energy Fuels 24 (3), 1860-1867. http:// dx.doi.org/10.1021/ef901413p.

Cai, J.C., Perfect, E., Cheng, C.-L., et al., 2014. Generalized modeling of spontaneous imbibition based on Hagen-Poiseuille flow in tortuous capillaries with variably shaped apertures. Langmuir 30 (18), 5142-5151. http://dx.doi.org/10.1021/ la5007204.

Crafton, James W., Noe, Sandra L., 2013. Factors Affecting Early Well Productivity in
Six Shale Plays. Presented at the SPE Annual Technical Conference and Exhibition. Society of Petroleum Engineers. http://dx.doi.org/10.2118/166101-MS.

Dehghanpour, H., Zubair, H.A., Chhabra, A., et al., 2012. Liquid intake of organic shales. Energy Fuels 26 (9), 5750-5758. http://dx.doi.org/10.1021/ef3009794.

Dutta, R., Lee, C.-H., Ddumabo, S., et al., 2014. Experimental investigation of fracturing- fluid migration caused by spontaneous imbibition in fractured lowpermeability sands. SPE Reserv. Eval. Eng. 17 (1), 74-81. http://dx.doi.org/10. 2118/154939-PA.

Engelder, T., Cathles, L.M., Bryndzia, L.T., 2014. The fate of residual treatment water in gas shale. J. Unconv. Oil Gas Resour. 7, 33-48. http://dx.doi.org/10.1016/j. juogr.2014.03.002.

Fakcharoenphol, P., Kurtoglu, B., Kazemi, H., et al., 2014. The Effect of Osmotic Pressure on Improve Oil Recovery from Fractured Shale Formations. Society of Petroleum Engineers. http://dx.doi.org/10.2118/168998-MS.

Ghanbari, E., Abbasi, M.A., Dehghanpour, H., Bearinger, D., 2013. Flowback Volumetric and Chemical Analysis for Evaluating Load Recovery and its Impact on Early-time Production. Society of Petroleum Engineers. http://dx.doi.org/10. 2118/167165-MS.

Habibi, Ali, Xu, Mingxiang, Dehghanpour, Hassan, 2015. Understanding rock-fluid interactions in the montney tight oil play. In: Presented SPE/CSUR Unconventional Resources Conference. Society of Petroleum Engineers. http://dx.doi.org/ 10.2118/175924-MS.

Jones, S.C., 1997. A technique for faster pulse-decay permeability measurements in tight rocks. SPE Form. Eval. 12 (01), 19-25. http://dx.doi.org/10.2118/28450-PA.

Li, C.X., Shen, Y.H., Ge, H.K., et al., 2016a. Analysis of spontaneous imbibition in fractal tree-like network system. Fractals 24 (03), 1650035 (12 pages). http://dx. doi.org/10.1142/S0218348X16500353.

Li, C.X., Shen, Y.H., Ge, H.K., et al., 2016b. Analysis of Capillary rise in asymmetric branch-like capillary. Fractals 24 (02), 1650024 (10 pages). http://dx.doi.org/10. 1142/S0218348X16500249.

Odumabo, S.M., Karpyn, Z.T., et al., 2014. Investigation of gas flow hindrance due to fracturing fluid leakoff in low permeability sandstones. J. Nat. Gas. Sci. Eng. 17, 1-12. http://dx.doi.org/10.1016/j.jngse.2013.12.002.

Palisch, T.T., Vincent, M., Handren, P.J., 2010. Slickwater fracturing: food for thought SPE Prod. Op. 25 (03), 327-344. http://dx.doi.org/10.2118/115766-MS.

Roychaudhuri, B., Tsotsis, T.T., Jessen, K., 2013. An experimental investigation of spontaneous imbibition in gas shales. J. Petrol. Sci. Eng. 111, 87-97. http://dx. doi.org/10.2118/162650-MS.

Roychaudhuri, B., Xu, J., Tsotsis, T.T., et al., 2014. Forced and spontaneous imbibition experiments for quantifying surfactant efficiency in tight shales. In: Presented at the Society of Petroleum Engineers Western North America and Rocky Mountain Joint Conference and Exhibition. Society of Petroleum Engineers. http://dx.doi.org/10.2118/169500-MS.

Soliman, M.Y., Daal, J., et al., 2012. Fracturing unconventional formations to enhance productivity. J. Nat. Gas Sci. Eng. 8 (0), 52-67. http://dx.doi.org/10.1016/j.jngse. 2012.01.007.

Wang, D., Butler, R., Zhang, J., et al., 2012. Wettability survey in bakken shale with surfactant-formulation imbibition. SPE Reserv. Eval. Eng. 15 (6), 695-705. http://dx.doi.org/10.2118/153853-PA.

Wang, Fengqin, Wang, Xiangzeng, Zhang, Lixia, et al., 2013. The shale gas resources estimation: an example from mesozoic triassic yanchang formation member Chang 7. Ordos basin. Earth Sci. Front. 20 (3), 240-246.

Yaich, E., Williams, S., Bowser, A., et al., 2015. A case study: the impact of soaking on well performance in the Marcellus. In: Paper 178614 Presented at the Unconventional Resources Technology Conference. Society of Petroleum Engineers. http://dx.doi.org/10.2118/178614-MS.

Yan, Q., Lemanski, C., et al., 2015. Experimental investigation of shale gas production impairment due to fracturing fluid migration during shut-in time. J. Nat. Gas Sci. Eng. 24, 99-105. http://dx.doi.org/10.1016/j.jngse.2015.03.017.

Yang, Liu, Ge, Hongkui, Shi, Xian, et al., 2016. The effect of microstructure and rock mineralogy on water imbibition characteristics in tight reservoirs. J. Nat. Gas Sci. Eng. 34, 1461-1471. http://dx.doi.org/10.1016/j.jngse.2016.01.002.

Zou, C.N., Dong, D.Z., Shejiao, W.A.N.G., et al., 2010. Geological characteristics, formation mechanism and resource potential of shale gas in China. Petrol. Explor Dev. 37 (06), 641-653. 